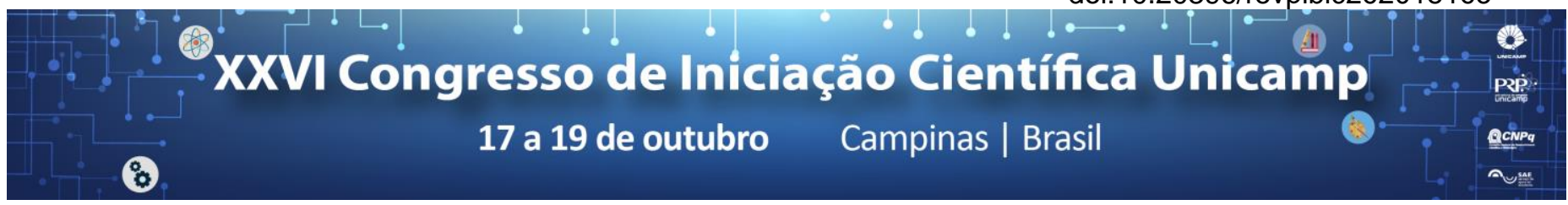

\title{
Screening de Líquidos lônicos Próticos para Fracionamento de Biomassa
}

\section{Antonio Arriva de Toledo*, Thaynara Coradini Pin, Aline Carvalho da Costa}

\section{Resumo}

De forma a avaliar a eficiência da realização de um pré-tratamento de bagaço de cana-de-açúcar para a produção de etanol de segunda geração, foram realizados pré-tratamentos com líquidos iônicos próticos (LIPs) sintetizados a partir da combinação de duas bases aminas e dois ácidos orgânicos para verificar a influência das bases e ácidos utilizadas no pré-tratamento do bagaço. Após isto, foi realizada uma etapa de otimização do pré-tratamento com a variação do tempo e da temperatura para o LIP que apresentou o melhor desempenho anteriormente.

\section{Palavras-chave:}

Pré-tratamento, líquido iônico, biomassa.

\section{Introdução}

Com a crescente preocupação com o meio ambiente, diversos estudos para fontes renováveis estão surgindo e buscando meios sustentáveis de geração de energia. Entre esses meios está a produção de etanol de segunda geração (E2G), que no Brasil é principalmente estudado usando bagaço de cana-de-açúcar.

O bagaço proveniente da produção de etanol de primeira geração é uma biomassa rica em polissacarídeos, celulose e hemiceluloses. Porém, a presença de lignina em sua estrutura, dificulta a conversão dos carboidratos em açúcares fermentescíveis pelas enzimas (ROCHA et al., 2017).

O presente projeto visa realizar uma triagem com 4 líquidos iônicos próticos (LIPs) e, consequentemente, selecionar o LIP com a melhor performance para otimização desse pré-tratamento.

\section{Resultados e Discussão}

O pré-tratamento foi realizado com as frações mássicas de $15 \%$ água, $75 \%$ LIP e $10 \%$ de bagaço seco, de forma que a massa total presente no reator fosse de $100 \mathrm{~g}$. Os ensaios foram realizados durante $2 \mathrm{~h}$ na temperatura máxima pré-estabelecida pela análise termogravimétrica do LIP.

A partir da determinação das composições de celulose, hemiceluloses e lignina após o pré-tratamento, foi possível calcular as solubilizações das frações.

Figura 1. Frações solubilizadas no pré-tratamento para cada LIP.

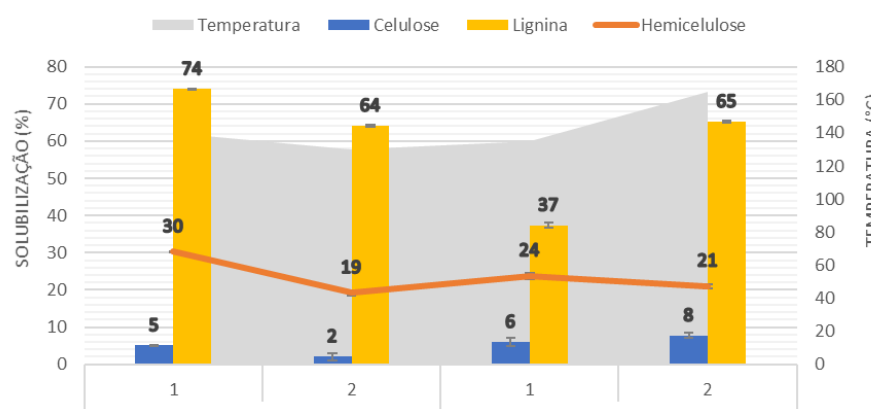

Com os dados de composição da biomassa prétratada junto aos dados de concentração de açúcares obtidos na hidrólise enzimática calculou-se a conversão de carboidratos em açúcares fermentescíveis.
Figura 2. Resultados de conversão de hidrólise para cada LIP.

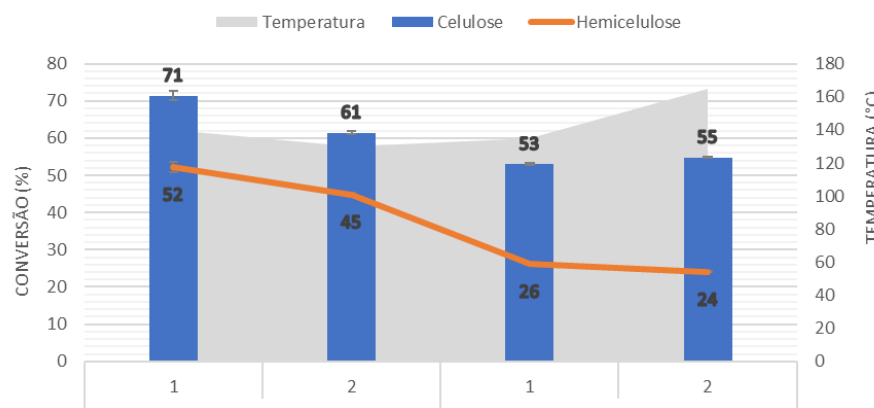

A partir desses resultados foi selecionado o LIP que se mostrou com melhor desempenho, o qual foi sintetizado pela combinação da base A com o ácido 1 .

Com este LIP foi realizada uma otimização de prétratamento com variação do tempo e da temperatura em um planejamento fatorial de $3^{2}$ com triplicata no ponto central. Os tempos utilizados foram de $1 \mathrm{~h}, 2 \mathrm{~h}$ e $3 \mathrm{~h}$ e as temperaturas foram de $140{ }^{\circ} \mathrm{C}, 150{ }^{\circ} \mathrm{C}$ e $160{ }^{\circ} \mathrm{C}$.

Com estes experimentos e uma análise mais aprofundada dos resultados foi possível constatar que o pré-tratamento que obteve os resultados mais positivos foi nas condições de $160 \stackrel{\circ}{\circ} \mathrm{C}$ por $3 \mathrm{~h}$ com valores de conversão de celulose e hemicelulose de $55,89 \%$ e $49,69 \%$, respectivamente, e solubilização de lignina de $49,17 \%$.

\section{Conclusões}

Com a realização de um screening de 4 LIPs sintetizados a partir da combinação de duas bases aminas e dois ácidos orgânicos pode-se chegar ao melhor LIP em questão de resultados do pré-tratamento. Após, com a etapa de otimização do pré-tratamento com esse LIP, chegou-se à conclusão que as melhores condições são a realização do pré-tratamento por 3 horas em uma temperatura de $160 \stackrel{\circ}{\circ}$, visto que este obteve os resultados mais promissores.

\section{Agradecimentos}

O autor gostaria de agradecer o suporte dado pela CNPq.

ROCHA, E. G. A.; PIN, T. C.; RABELO, S. C.; COSTA, A. C.. Evaluation of the use of protic ionic liquids on biomass fractionation. Fuel, v. 206, p. 145 154, 2017. 